\title{
ORIGINAL
}

\section{Effect of epigenetic modulation on cancer sphere}

\author{
Shuichi Iwahashi M.D., Mitsuo Shimada M.D., Yuji Morine M.D., Satoru Imura M.D., Tetsuya Ikemoto M.D., \\ Yu Saito M.D., Shinihiro Yamada M.D., and Tohru Utsunomiya M.D. \\ Department of Surgery, Institute of Health Biosciences, The University of Tokushima Graduate School, Tokushima, Japan
}

\begin{abstract}
Background : Cancer stem cell properties are highly relevant to the biology of treatment-resistant cancers. Epigenetic modification regulates gene expressions by chromatin remodeling during malignant transformation. The aim of this study was to elucidate the possible strategy for cancer stem cells focusing on epigenetic modification. Methods: We made cancer sphere from HepG2 cells, and we added Histone deacetylase (HDAC) inhibitor, valproic acid to cancer sphere. And we compared methylation status and the gene expression between normal HepG2 and cancer sphere groups, and between cancer sphere and sphere with HDAC inhibitor treatment groups. Results : Valproic acid (VPA) cancelled this spheroid formation. In comparison between normal HepG2 and cancer sphere, the number of methylation status changes more than 0.1 of beta level was 826 probes, and we could isolate some epithelial-mesenchymal transition (EMT) related genes. And VPA reduced the expressions of EMT related genes in sphere with RT-PCR. On the other hand, in comparison between cancer sphere and sphere with VPA treatment, we detected 29 probe of methylation status change, and VPA reduced the expressions of Bcl6 in sphere. Conclusions : HDAC inhibitor affected the methylation status of cancer stem cells. Histone-acetylation might overcome treatmet-resistant cancer through the regulation of cancer stem cell. J. Med. Invest. 67: 70-74, February, 2020
\end{abstract}

Keywords : Cancer stem cell, Sphere, Epigenetic modulation, Valproic acid, DNA methylation

\section{INTRODUCTION}

Hepatocellular carcinoma (HCC) is one of the most frequent cancers, and this is not only a leading cause of cancer-related deaths, but is also significantly increasing globally $(1,2)$. Despite short-term improvement afforded by surgical resection, local ablation therapy, transarterial chemoembolization, and liver transplantation, long-term outcome is still unsatisfactory in HCC patients (3-5).

Tumors contain the small subpopulations of cells called cancer stem cells (CSC) (6-9), and these cells are able to proliferate and self-renew extensively because of their ability to express anti-apoptotic and drug-resistant proteins, thus sustaining tumor growth (10).

Alterations in the epigenetic modulation of gene-expressions have been implicated in cancer development and progression. Histone acetylation is a post-translational modulation of the nucleosomal histones that affects chromatin structure and modulates gene-expressions. Histone deacetylases (HDACs) comprise an ancient family of enzymes that play crucial roles in numerous biological processes (11) and expressions of HDACs are upregulated in many tumor types $(12,13)$. Therefore, HDAC inhibitors are promising as novel anticancer agents, and in this study we used Valproic acid (VPA), which has been shown to have anticancer effects in various cancer models (14-18).

And then, DNA methylation is observed in many human cancers, including HCC, in which global hypomethylation and specific promoter hypermethylation have been found as typical epigenetic changes involved in genomic instability and silencing of tumor suppressor genes, respectively $(19,20)$. Regarding the

Received for publication July 18, 2019 ; accepted October 9, 2019.

Address correspondence and reprint requests to Shuichi Iwahashi, M.D., Department of Surgery, Institute of Health Biosciences, The University of Tokushima, 3-18-15 Kuramoto-cho, Tokushima, 7708503, Japan and Fax : +81-88-631-9698. relationship between epigenetic modification and cancer stem cell property, Nalls D et al. reported the possibility of epigenetic modification reduced cancer stem cell property and epigenetic modification may be promising reagents to boost the patient response to existing chemotherapies or as a standard cancer drug (21). However, there were numerous examples of aberrant DNA methylation, little is known about the global picture of hyper- or hypomethylated genes in CSC.

The aim of this study was to investigate the possible strategy for CSC through the epigenetic modification.

\section{MATERIAL AND METHOD}

\section{Cell lines and culture conditions}

HepG2 was provided by the RIKEN BRC through the National Bio-Resource Project of the MEXT, Japan. All cell lines were grown in RPMI 1640, supplemented with $10 \%$ fetal bovine serum (FBS), $70 \mu \mathrm{g} / \mathrm{mL}$ penicillin, $100 \mu \mathrm{g} / \mathrm{mL}$ streptomycin (complete medium), and maintained at $37^{\circ} \mathrm{C}$ in a humidiWed incubator with $5 \% \mathrm{CO} 2$ in the air. The cells were maintained for no longer than 12 weeks after recovery from frozen stock.

\section{Sphere formation}

Cells were collected and washed to remove serum, then suspended in serum-free DMEM/F12 (Invitrogen) supplemented with $100 \mathrm{IU} / \mathrm{ml}$ penicillin, $100 \mu \mathrm{g} / \mathrm{ml}$ streptomycin, $20 \mathrm{ng} / \mathrm{ml}$ human recombinant epidermal growth factor (EGF) and $10 \mathrm{ng} /$ $\mathrm{ml}$ human recombinant basic fibroblast growth factor (bFGF) (R\&D systems, Minneapolis, MN, USA), 2\% B27 supplement without vitamin A and 1\% N2 supplement (Invitrogen, Carlsbad, CA, USA). The cells were subsequently cultured in ultra low attachment 6 -well plates (Corning Inc., Corning, NY, USA) at a density of not more than $1 \times 10^{5}$ cells/well with or without $1.0 \mathrm{mM}$ of VPA for 24 hours or 48 hours. The pictures of cells were taken by microscope (100x), (Inverted Microscope, Nikon TE2000-U, Japan) 


\section{Reagents}

Valproic acid was purchased from Wako Pure Chemical Industries, Ltd. (Osaka, Japan), kept at $4^{\circ} \mathrm{C}$, and diluted in PBS as necessary at the time of use.

\section{Array-Based Analysis of DNA Methylation}

Genomic DNA was extracted from HepG2 cell. Bisulfite conversion of $500 \mathrm{ng}$ of genomic DNA was performed with the EZ DNA methylation kit (Zymo Research). DNA methylation level was assessed with Infinium ${ }^{\circledR}$ HumanMethylation450 BeadChips (Illumina Inc.). Quantitative measurements of DNA methylation were determined for 485,764 CpG dinucleotides that covered $99 \%$ of the RefSeq genes and were distributed across whole gene regions, including promoters, gene bodies, and 3'-UTRs. Detailed information on the contents of the array is available in the Infinium HumanMethylation450 User Guide, HumanMethylation450 manifest (www.illumina.com) and recent papers. DNA methylation data was analyzed using the methylation analysis module within the BeadStudio software (Illumina Inc.). DNA methylation statuses of the $\mathrm{CpG}$ sites were calculated as the ratio of the signal from a methylated probe relative to the sum of both methylated and unmethylated probes. These values, known as $\beta$, ranges from 0 (completely unmethylated) to 1 (fully methylated) $(22,23)$. The genes in $\beta$-value difference $>0.1$ and $\mathrm{P}<0.05$ were detected.

And then, we used Ingenuity Pathway Analysis (IPA) 8.7 (http://www.ingenuity.com) to determine the functional pathways associated with the set of differentially expressed genes between genotypes. IPA utilizes the knowledge in the literature about biological interactions among genes and proteins.

\section{RNA isolation and quantitative real time RT-PCR}

The extracted RNA was reversed, transcribed with High Capacity cDNA Reverse Transcription Kit (Applied Biosyste$\mathrm{ms})$. Quantitative real-time RT-PCR was performed using the Applied Biosystems 7500 real-time PCR system, TaqMan Gene Expression Assays-on-demand, and the TaqMan Universal Master Mix (Applied Biosystems). The following assays (assay identification number) were used : CXCL5 (Hs01099660_g1), Bmi1 (Hs00180411_m1), Bcl-6 (Hs00153368_m1) and PIK3CA (Hs00907957_m1). TaqMan Human ACTB Endogenous Control $(4326315 \mathrm{E})$ was used as a control gene. The thermal cycler conditions were as follows : 2 minutes at $50^{\circ} \mathrm{C}, 10$ minutes at $95^{\circ} \mathrm{C}, 40$ cycles of 15 seconds at $95^{\circ} \mathrm{C}$, and 1 minute at $60^{\circ} \mathrm{C}$. Amplification data were analyzed with an Applied Biosystems Prism 7500 Sequence Detection System version 1.3.1 (Applied Biosystems).

\section{Statistical analyses}

Statistical comparisons of mean values were conducted using one-way ANOVA. All the results are presented as mean $\pm \mathrm{SD}$. All statistical analysis was performed using statistical software (JMP 8.0.1., SAS Campus Drive, Cary, NC). A $P$ value of less than 0.05 was considered to be statistically significant.

\section{RESULTS}

HepG2 well developed to cancer sphere, and VPA cancelled this spheroid formation with time dependent. $48 \mathrm{hr}$ after VPA treatment, spheroid formation was completely cancelled (Fig. 1).

In comparison between normal HepG2 and cancer sphere, the number of methylation status changes more than 0.1 of beta level was 826 probes. And hyper- and hypo-methylation changes were identified in 425 and 401 probe, respectively. Of these hypo-methylation changes, we could isolate some epithelial-mesenchymal transition (EMT) related genes like SDF-1, CXCL5 and IGFR1 (Fig. 2). In real-time RT-PCR, VPA reduced the CXCL5 expression compared to that of sphere with time $(\mathrm{P}<0.01)$ (Fig. $3 \mathrm{~A})$. And regarding as other EMT relataed genes, Bmi1, we could get the similar data as CXCL5 (Fig. 3B). And we investigated the gene network with IPA analysis, IPA represented down-regulated (green) genes in the gene network of the "Tumor Development" in comparison between normal HepG2 and cancer sphere (Fig. 4).

On the other hand, in comparison between cancer sphere and sphere with VPA treatment, we detected 29 probe of methylation status change. And hyper- and hypo-methylation changes were identified in 20 and 9 probes, respectively.

Especially in cell growth related gene, Bcl- 6 changed to hyperand PIK3CA changed to hypo-methylation status (Fig. 5).

In regard to the gene expressions, the down-regulation of the Bcl-6 expression in the sphere with VPA was confirmed by RT-PCR compared to the only sphere group with time $(\mathrm{P}<0.01)$ (Fig. 6A). And then, the PIK3CA expression in the sphere with VPA tended to increase compared to that in only sphere group $(\mathrm{P}=0.08)$ (Fig. 6B).
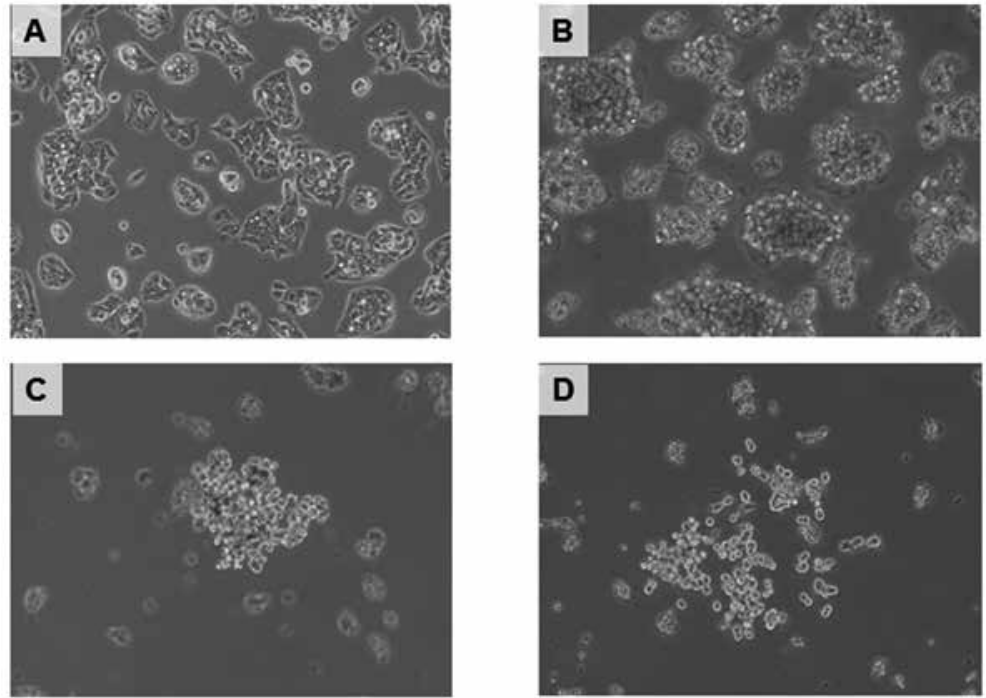

Figure 1 : The morphological changes of HepG2 (A), sphere (B), sphere with VPA 24 hours (C) and sphere with VPA 48 hours (D) 
(\%)

425 probe hyper-methylation

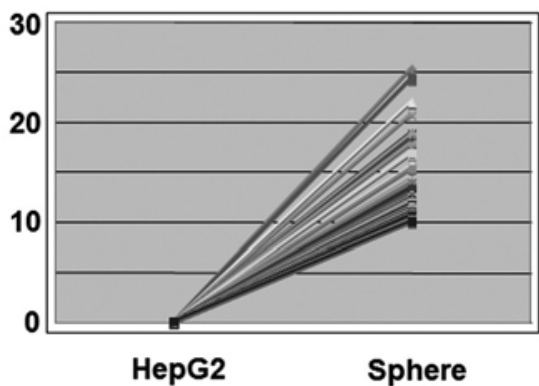

Apoptosis and autophagy
: Caspase 9

Metabolism : Cyp4X1

Angiogenesis: Adrenomedullin 2
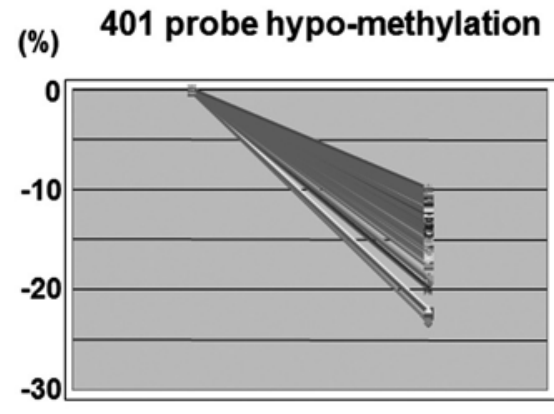

HepG2

Cell migration and invasion

: CXCL12 (SDF-1), CXCL5, CD9

Proliferation : IGFR1

Inflammation: S100A9

Figure 2 : The methylation status changes in comparison between normal HepG2 and cancer sphere

A

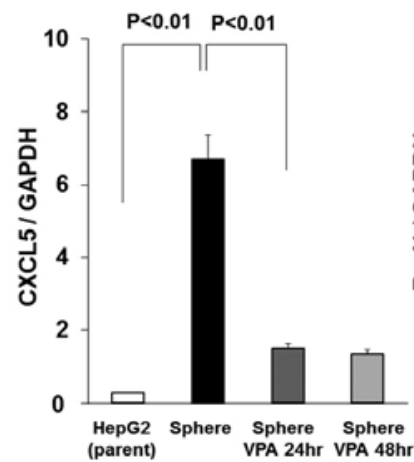

B

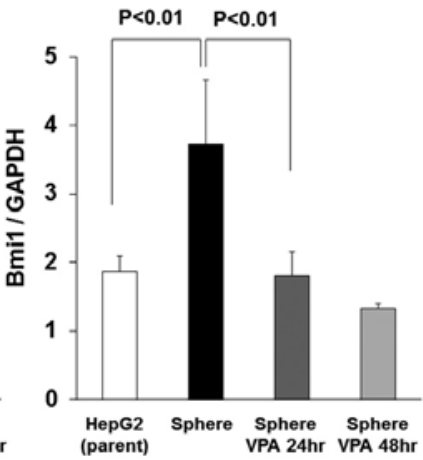

Figure 3 : The gene-expressions of CXCL5 (A) and Bmi1 (B) with RTPCR
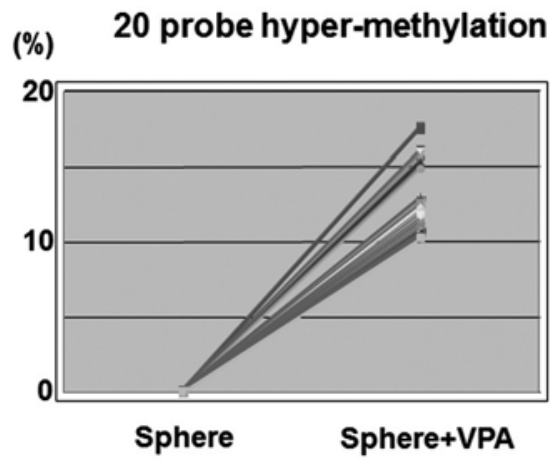

Cell proliferation : Bcl6

ABC transporters : ABCA6 Differentiation : SORBS2

\section{(\%) 9 probe hypo-methylation}

Figure 4 : The gene network with the genes isolated in comparison between normal HepG2 and cancer sphere using IPA

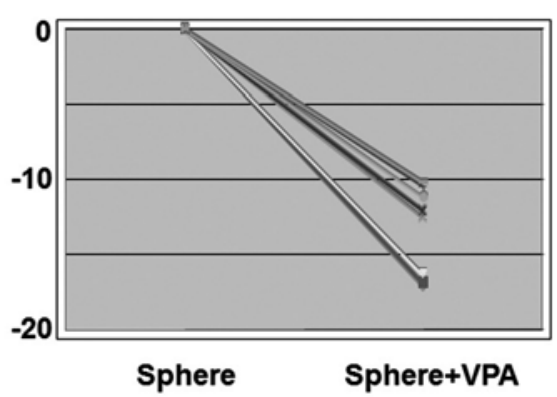

Cell proliferation : PIK3CA

Catabolic process : PSMC2

Figure 5 : The methylation status changes in comparison between cancer sphere and sphere with VPA treatment 
A

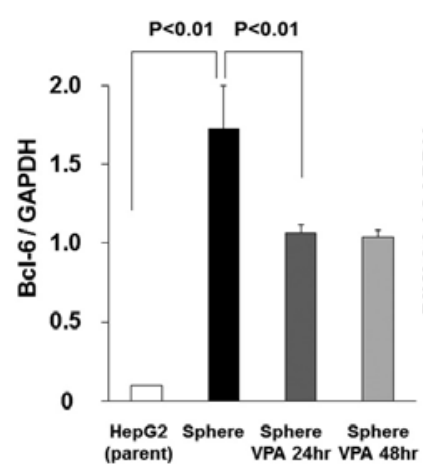

B

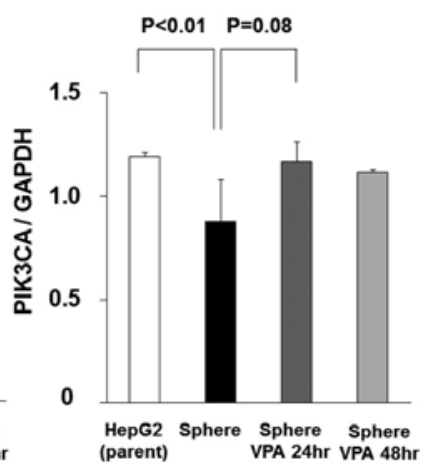

Figure 6 : The gene-expressions of Bcl-6 (A) and PIK3CA (B) with RT-PCR

\section{DISCUSSION}

In the present study, we assessed the epigenetic modulation in cancer stem cell, especially sphere formation with VPA on hepatoma cell line. To the best of our knowledge, this is the first report showing epigenetic modulation in cancer stem cell with methylation array.

In comparison between normal HepG2 and sphere, we could isolate some EMT related genes in hypo-methylation changes. The relationships between stemness characteristics and EMT phenomena have been reported in recent manuscripts. Researchers found that EMT acquires CSC properties, increases cancer cell tumorigenicity (24-26). In this study, VPA reduced the EMT related gene expressions and cancelled sphere formation, therefore these manuscripts are consistent with our findings.

In comparison between cancer sphere and sphere with VPA treatment, Bcl- 6 changed to hyper- and PIK3CA changed to hypo-methylation status in cell growth related gene. Pellicano $\mathrm{F}$ et al. suggested leukemia cancer stem cell survival related to Bcl6 and PIK3CA, and these factors were inversely correlated (27). HDAC inhibitor, VPA seems to inhibit cancer stem cell survival through the epigenetic blocking in this pathway.

And then, we revealed HDAC inhibitor affected to methylation status changes. Zopf S et al. demonstrated that HDAC inhibitor reduced DNA methyltransferase (DNMT) activity and loss of DNMT activity was paralleled by a diminished methylation of the target gene in HepG2 cells (28). In other words, HDAC inhibitor can regulate the methylation status through the inhibition of DNMT.

VPA may have the effects to CSC in HepG2 cells in this study. However, some of the HDAC inhibitors are of limited therapeutic use due to the toxic side effects at high doses (29). VPA is widely used as a therapeutic drug for epilepsy and its toxic profile and pharmacokinetic properties are well established. Furthermore, in our study, the promising dose of VPA was $1.0 \mathrm{mM}$, while the peak plasma concentration in patients treated for epilepsy ranges between 0.5 and $1.2 \mathrm{mM}$ (30). VPA, at a dose of $1.0 \mathrm{mM}$, may not cause any serious side effects in clinical setting.

In conclusion, VPA, one of the HDAC inhibitor, affected the methylation status of EMT related genes and cell growth related genes of cancer stem cells. Histone-acetylation might overcome treatmet-resistant cancer through the regulation of cancer stem cell.

\section{CONFLICTS OF INTEREST}

We have no conflicts of interest or financial ties to disclose.

\section{ACKNOWLEDGEMENTS}

We have no conflicts of interest or financial ties to disclose. We thank Ms. Nami Harada, Aki Matsumoto and Yumiko Takeuchi for their support in the performance of this study.

\section{REFERENCES}

1. Llovet JM, Burroughs A, Bruix J : Hepatocellular carcinoma. Lancet $362: 1907-1917,2003$

2. Farazi PA, DePinho RA : Hepatocellular carcinoma pathogenesis : from genes to environment. Nat Rev Cancer $6: 674-687,2006$

3. El-Serag HB : Hepatocellular carcinoma : an epidemiologic view. J Clin Gastroenterol 35 : 72-78, 2002

4. Huang YH, Chen CH, Chang TT, Chen SC, Wang SY, Lee PC, Lee HS, Lin PW, Huang GT, Sheu JC, Tsai HM, Chau GY, Chiang JH, Lui WY, Lee SD, Wu JC : The role of transcatheter arterial embolization in patients with resectable hepatocellular carcinoma : a nation-wide, multicenter study. Liver Int 24 : 419-424, 2004

5. Wubetu GY, Utsunomiya T, Ishikawa D, Yamada S, Ikemoto T, Morine Y, Iwahashi S, Saito Y, Arakawa Y, Imura S, Kanamoto M, Zhu C, Bando Y, Shimada M : High STAT4 expression is a better prognostic indicator in patients with hepatocellular carcinoma after hepatectomy. Ann Surg Oncol 21 Suppl 4 : S721-728, 2014

6. Jordan CT, Guzman ML, Noble M : Cancer stem cells. N Engl J Med 355 : 1253-1261, 2006

7. Dalerba P, Cho RW, Clarke MF : Cancer stem cells : models and concepts. Annu Rev Med 58:267-284, 2007

8. Shimada M, Sugimoto K, Iwahashi S, Utsunomiya T, Morine Y, Imura S, Ikemoto T : CD133 expression is a potential prognostic indicator in intrahepatic cholangiocarcinoma. J Gastroenterol 45 : 896-902, 2010

9. Lin CH, Shen YA, Hung PH, Yu YB, Chen YJ : Epigallocathechin gallate, polyphenol present in green tea, inhibits stem-like characteristics and epithelial-mesenchymal transition in nasopharyngeal cancer cell lines. BMC Complement Altern Med $12: 201,2012$

10. Frame FM, Maitland NJ : Cancer stem cells, models of study and implications of therapy resistance mechanisms. Adv Exp Med Biol 720 : 105-118, 2011

11. Haberland M, Montgomery RL, Olson EN : The many roles of histone deacetylases in development and physiology : Implications for disease and therapy. Nat Rev Genet $10: 32-42$, 2009

12. Patra SK, Patra A, Dahiya R : Histone deacetylase and DNA methyltransferase in human prostate cancer. Biochem Biophys Res Commun 287 : 705-713, 2001

13. Lin RJ, Nagy L, Inoue S, Shao W, Miller WH Jr, Evans RM : Role of the histone deacetylase complex in acute promyelocytic leukaemia. Nature 391 : 811-814, 1998

14. Göttlicher M, Minucci S, Zhu P, Krämer OH, Schimpf A, Giavara S, Sleeman JP, Lo Coco F, Nervi C, Pelicci PG, Heinzel T, Valproic acid defines a novel class of HDAC inhibitors inducing differentiation of transformed cells. EMBO J $20: 6969-6978,2001$

15. Jones J, Bentas W, Blaheta RA, Makarevic J, Hudak L, Wedel S, Probst M, Jonas D, Juengel E : Modulation of 
adhesion and growth of colon and pancreatic cancer cells by the histone deacetylase inhibitor valproic acid. Int J Mol Med 22 : 293-299, 2008

16. Iwahashi S, Shimada M, Utsunomiya T, Morine Y, Imura S, Ikemoto T, Mori H, Hanaoka J, Saito Y : Histone deacetylase inhibitor enhances the anti-tumor effect of gemcitabine : a special reference to gene-expression microarray analysis. Oncol Rep 26 : 1057-1062, 2011

17. Iwahashi S, Shimada M, Utsunomiya T, Morine Y, Imura S, Ikemoto T, Mori H, Hanaoka J, Sugimoto K, Saito Y : Histone deacetylase inhibitor augments anti-tumor effect of gemcitabine and pegylated interferon- $\alpha$ on pancreatic cancer cells. Int J Clin Oncol 16 : 671-678, 2011

18. Iwahashi S, Ishibashi H, Utsunomiya T, Morine Y, Ochir TL, Hanaoka J, Mori H, Ikemoto T, Imura S, Shimada $\mathrm{M}$ : Effect of histone deacetylase inhibitor in combination with 5-fluorouracil on pancreas cancer and cholangiocarcinoma cell lines. J Med Invest 58 : 106-109, 2011

19. Issa JP: CpG island methylator phenotype in cancer. Nat Rev Cancer 4 : 988-993, 2004

20. Matsuzaki K, Deng G, Tanaka H, Kakar S, Miura S, Kim YS : The relationship between global methylation level, loss of heterozygosity, and microsatellite instability in sporadic colorectal cancer. Clin Cancer Res 11: 8564-8569, 2005

21. Nalls D, Tang SN, Rodova M, Srivastava RK, Shankar $\mathrm{S}$ : Targeting epigenetic regulation of miR-34a for treatment of pancreatic cancer by inhibition of pancreatic cancer stem cells. PLoS One 6 : e24099, 2011

22. Kinoshita M, Numata S, Tajima A, Shimodera S, Imoto I, Ohmori T : Plasma total homocysteine is associated with DNA methylation in patients with schizophrenia.
Epigenetics 8: 584-590, 2013

23. Utsunomiya T, Shimada M, Morine Y, Tajima A, Imoto I : Specific molecular signatures of non-tumor liver tissue may predict a risk of hepatocarcinogenesis. Cancer Sci 105 : 749-754, 2014

24. Kong D, Banerjee S, Ahmad A, Li Y, Wang Z, Sethi S, Sarkar $\mathrm{FH}$ : Epithelial to mesenchymal transition is mechanistically linked with stem cell signatures in prostate cancer cells. PLoS One 5 : e12445, 2010

25. Hollier BG, Evans K, Mani SA : The epithelial-to-mesenchymal transition and cancer stem cells : a coalition against cancer therapies. J Mammary Gland Biol Neoplasia 14 : 2943, 2009

26. Polyak K, Weinberg RA : Transitions between epithelial and mesenchymal states : acquisition of malignant and stem cell traits. Nat Rev Cancer 9 : 265-273, 2009

27. Pellicano F, Holyoake TL : Assembling defenses against therapy-resistant leukemic stem cells : Bcl6 joins the ranks. J Exp Med 208 : 2155-2158, 2011

28. Zopf S, Ocker M, Neureiter D, Alinger B, Gahr S, Neurath MF, Di Fazio P : Inhibition of DNA methyltransferase activity and expression by treatment with the pan-deacetylase inhibitor panobinostat in hepatocellular carcinoma cell lines. BMC Cancer $12: 386,2012$

29. Warrell RP Jr, He LZ, Richon V, Calleja E, Pandolfi PP : Therapeutic targeting of transcription in acute promyelocytic leukemia by use of an inhibitor of histone deacetylase. J Natl Cancer Inst 90 : 1621-1625, 1998

30. Blaheta RA, Michaelis M, Driever PH, Cinatl J Jr : Evolving anticancer drug valproic acid : insights into the mechanism and clinical studies. Med Res Rev 25 : 383-397, 2005 